\title{
Residual Stress, Phase, Microstructure and Mechanical Property Enhancement of Ultrafine Bainitic Steel through Laser Shock Processing
}

\author{
S. Prabhakaran ${ }^{a *}$, S. Kalainathan ${ }^{a *}$, Pratik Shukla $^{\text {b }}$, Vijay K. Vasudevan ${ }^{c}$ \\ ${ }^{a}$ Centre for Crystal Growth, Department of Physics, School of Advanced Sciences, Vellore Institute of Technology, Vellore - 632 \\ 014, Tamilnadu, India \\ ${ }^{b}$ School of Mechanical, Aerospace and Automotive Engineering, Coventry University, Priory Street, Coventry, CV1 5FB, United \\ Kingdom \\ ${ }^{c}$ Department of Mechanical and Materials Engineering, University of Cincinnati, OH 45221-0072, United States
}

*Corresponding authors E-mail: spkaran.kmd@gmail.com (S. Prabhakaran); kalainathan@yahoo.com (S. Kalainathan)

\begin{abstract}
The study proposes laser shock peening without a coating of high strength ultrafine bainitic steel to mitigating the fatigue failures for automotive and structural engineering applications. Laser pulse density of 2500 pulses $/ \mathrm{cm}^{2}$ (75\% overlapping) was optimised based on the induced residual stresses for employing the wide range of characterisations. The roughness and topographic results showed that surface roughening was controlled by tuning the laser pulse density. The High-Resolution X-ray Diffraction analysis confirmed the lattice misorientation resulting peak shift and the trend towards martensite phase transformations. The electron microscopic micro/nanostructure analyses revealed the grain refinement features such as nanotwins, micro shear bands and shear cells. The work hardening depth and nanomechanical properties were significantly enhanced. A fully reversed $(R=-1)$ high-cycle fatigue tests extended the lifespan by an average of fifteen times than the untreated. Also, it has potential to repair the structural components effectively.
\end{abstract}

Keywords: Laser shock peening (LSP); Bainitic ferrites; Plastic deformation; Hardness; Fatigue 


\section{Introduction}

The microstructure of sans carbide bainitic steel comprises of bainitic ferrite sheaves, carbon-enhanced retained austenite that may in some cases contain martensite, bringing about a remarkable blend of quality and strength. Further, it can be compared to quenched and tempered low carbon steels, thus, making it an excellent entrant for manufacturing of railway tracks and automotive parts. Since the last few decades, this silicon-rich sans-carbide bainitic steel has found its way to the automobile industry [1]. It was discovered that bainitic microstructure could achieve high strength and toughness in high carbon, silicon rich steels by transformation at low temperatures [2]. The bainitic microstructure in high-silicon steel comprises of bainitic ferrite $\left(\alpha_{b}\right)$ sheaves isolated through carbon-enhanced retained austenite $(\gamma)$. The high silicon content forestalls the development of carbides. The microstructure may likewise contain some martensite $(\alpha)$, acquired from the retained austenite. The martensitic ferrite $(\alpha)$ is created amid the last cooling from isothermal heat treatment when the temperature falls beneath the martensite start (Ms) temperature [3]. The carbide deficiency provides a higher opposition to cleavage crack and void development [4]. The volume fraction of retained austenite in the microstructure is responsible for controlling the ductility. The properties like strengthened toughness are procured from bainitic ferrite sheaves [5]. Bhadeshia et al.[3] discovered that elevating the volume fraction of bainite by $25 \%$ in a microstructure incorporating martensite resulted in maximum yield strength.

The highest achievable strength of the material surface thus helps to improve its resistance to crack initiation. The damage forbearance of material is portrayed by its fracture toughness and narrates under which loading conditions deformities or cracks proliferate [6][7][8]. Most of the fatigue cracks are initiated at the surface and propagate throughout the material leading to fatigue failure. Hence, to prevent this need for surface modification is playing a vital role [9][10]. The laser surface processing techniques are emerging from a decade because of its all-round performance in reliability and consistency of performance in industries. The laser materials processing techniques like laser melting and laser shock peening (LSP) become getting vital importance [11]. As soon as the induced shock pressure during LSP increases higher than the dynamic yield strength of the material (Hugoniot Elastic Limit), the plastic deformation and compressive residual stress induced in the surface and the subsurface layer of the workpiece. 
LSP is one of the superior surface modification technologies; a cold working process that can induce compressive residual stress through a number of successive shots/passes of laser pulses [12]. These residual stresses can retard the fatigue crack initiation and propagations effectively [13].

Montross et al.[13] demonstrated that LSP causes beneficial microstructural changes in the material surface and in this way the specimen's mechanical performance was enhanced. The fundamental concept behind LSP with the metallic specimen in water imprisonment can be clarified as takes after. When a laser pulse focused at a point on a sample which is covered by water confinement medium, the specimen's surface layer dissipates instantaneously as soon as it comes in contact with the laser. The vapour consistently assimilates the laser energy for the whole pulse duration, and this process transmutes the vapour to high-temperature plasma. The water layer traps the exceptionally extending plasma towards the specimen's surface and induces intense shock waves of peak pressure of the order of a few GPa. [14]. The yield strength and microhardness of metallic materials and alloys increased when the grain size decreased, and it is given by Hall-Petch relationship [15]. Later, a thermo-mechanical impact of LSP, called laser peening without coating (LSPwC) developed by Sano and Mukai et.al.[16] as a preventive upkeep innovation against stress corrosion cracking (SCC). Conventional LSP works with protective ablation coatings covered with the metal surface, like black ink or Al foils or polyvinyl chloride tape. The ablation coating protects the surface quality from high energy laserinduced thermal damage. The advantages of LSPwC include: (1) It is applicable for direct treatment of nuclear plant components during maintenance with low laser pulse energies less than 1 Joule; (2) Surface chemistry of the treated material not altered. The probability of generating residual tensile stress on few microns of the top surface was a major drawback of the laser shock peening without coating (LSPwC) process, which is due to the higher thermal effect, the surface melting and re-solidification occurring on the surface. As a consequence, it affects the magnitude of compressive residual stress generation. Hence, a low energy laser is found to be a right solution to eliminate these issues by optimising the experimental parameters. A low energy Nd: YAG laser identified as the most reliable surface modification apparatus since, the high energy Nd: glass lasers produce large coverage area, and as a result, one needs to sacrifice surface quality especially during severe LSP [14][16]. LSPwC on stainless steel 304 and 316L were accounted by Sano and Mukai et al.[16] utilising the second harmonic of $532 \mathrm{~nm}$ laser. 
Their research illustrated that LSPwC was an efficient technique for inducing compressive residual stress on the specimen's surface and prompts interception of SCC and enhances fatigue strength. A high energy laser costs and reliability problems are the major limitations for the LSP to be readily implemented [17][18].

State of the art of this work is to find a pathway for low energy LSPwC process to be a successful potential replacement for an already prevalent surface modification technique like shot peening and can be utilised in automotive and various structural engineering applications. The aim is to examine and outline the utilisation of LSPwC by the low energy Nd: YAG laser for an enhanced surface treatment process and constitute ideal parameters for upgrading the fatigue properties of SAE 9254 spring steel. The work above is designed in such a way that it includes a wide range of post material characterisations to understand the surface properties of bainitic spring steel. To the best of our knowledge, LSP induced deformation in bainitic ferrites and its effects on surface microstructure and mechanical properties has not been reported in the literature so far, which is one of the first motivations of this research. It is well known that for several structural engineering applications, the bainitic, ferrite and martensitic composite phase microstructure is the best suitable one to address the highest mechanical properties. So the surface properties of these steels are required to improve to improve their fatigue life.

\section{Experiments and methods}

\subsection{Metallographic specimen preparation and laser shock peening without coating $(\operatorname{LSP} w \boldsymbol{C})$}

The hot rolled (around $1000^{\circ} \mathrm{C}$ ) SAE 9254 spring steel sheet has the dimension of 160x160x20 mm received from JSW Steel Ltd, Salem works, India and it has been cut into 20x20x5 mm pieces for this study, by wire-cut electrical discharge machining (EDM). The chemical composition of as-received specimen tested by optical emission spectrometry (OES) method (ARL. Quantris Spark Analyzer, Thermo Electron, SWISS). The chemical composition has confirmed that the tested specimen grade is medium carbon high content of $\mathrm{Si}, \mathrm{Cr}$ and $\mathrm{Mn}$ alloyed SAE 9254 spring steel. The chemical composition of the material SAE 9254 is as shown in the Table-1. The austenitization process was carried out in a box muffle furnace at $900{ }^{\circ} \mathrm{C}$ for 30 minutes; the samples were air cooled to $400{ }^{\circ} \mathrm{C}, 350{ }^{\circ} \mathrm{C}, 300{ }^{\circ} \mathrm{C}, 250{ }^{\circ} \mathrm{C}$ and next isothermally held at the chosen temperature for 15 minutes, respectively and the schematic 
representation is given in Fig.1a. Followed by hardening, immediately the specimens are processed for tempering treatment at $250{ }^{\circ} \mathrm{C}$ for $3 \mathrm{hrs}$. The experiment was performed with constant low energy (300 mJ) Nd: YAG laser (LPY704G-10, Litron Lasers Ltd., Rugby, UK) with the fundamental wavelength of $1064 \mathrm{~nm}$ and the pulse duration of $10 \mathrm{~ns}$ for different pulse densities or overlapping. The exhibited radiance density (laser beam brightness) was of 258.78 $\mathrm{mW} . \mathrm{cm}^{2} . \mathrm{Sr}^{-1} \mu \mathrm{m}$ determined and stated in Table.2. The laser comprised of an $\mathrm{M}^{2}$ (beam quality factor) value of 2 and a beam divergence of $0.8 \mathrm{mrad}$. The beam shape was a top hat profile, and

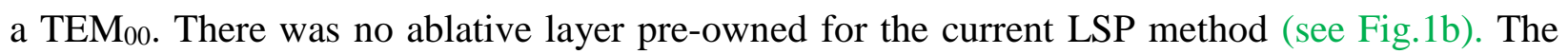
decarburised surface of a few micrometres on the surface of the specimen was removed by grinding, and the polished mirror surface was prepared for the experiments and characterisations (see Fig.1c). The LSP parameters are listed in the Table-2.

Table 1: Chemical composition of as-received SAE 9254 spring steel

\begin{tabular}{|l|l|l|l|l|l|l|l|l|l|l|l|l|}
\hline $\mathrm{C}$ & $\mathrm{Si}$ & $\mathrm{Mn}$ & $\mathrm{P}$ & $\mathrm{S}$ & $\mathrm{Ni}$ & $\mathrm{Cr}$ & $\mathrm{Mo}$ & $\mathrm{V}$ & $\mathrm{Cu}$ & $\mathrm{W}$ & $\mathrm{Ti}$ & $\mathrm{Sn}$ \\
\hline 0.56 & 1.35 & 0.64 & 0.002 & 0.002 & 0.018 & 0.72 & 0.002 & 0.008 & 0.019 & 0.013 & 0.004 & 0.007 \\
\hline $\mathrm{Co}$ & $\mathrm{Pb}$ & $\mathrm{B}$ & $\mathrm{Sb}$ & $\mathrm{Nb}$ & $\mathrm{Zr}$ & $\mathrm{Bi}$ & $\mathrm{Ca}$ & $\mathrm{Mg}$ & $\mathrm{Zn}$ & $\mathrm{Ce}$ & $\mathrm{La}$ & $\mathrm{Fe}$ \\
\hline 0.004 & 0.001 & 0.0008 & 0.022 & 0.003 & 0.002 & 0.0009 & 0.002 & 0.0003 & 0.0007 & 0.002 & 0.008 & 96.53 \\
\hline
\end{tabular}

The elements are in weight $\%$

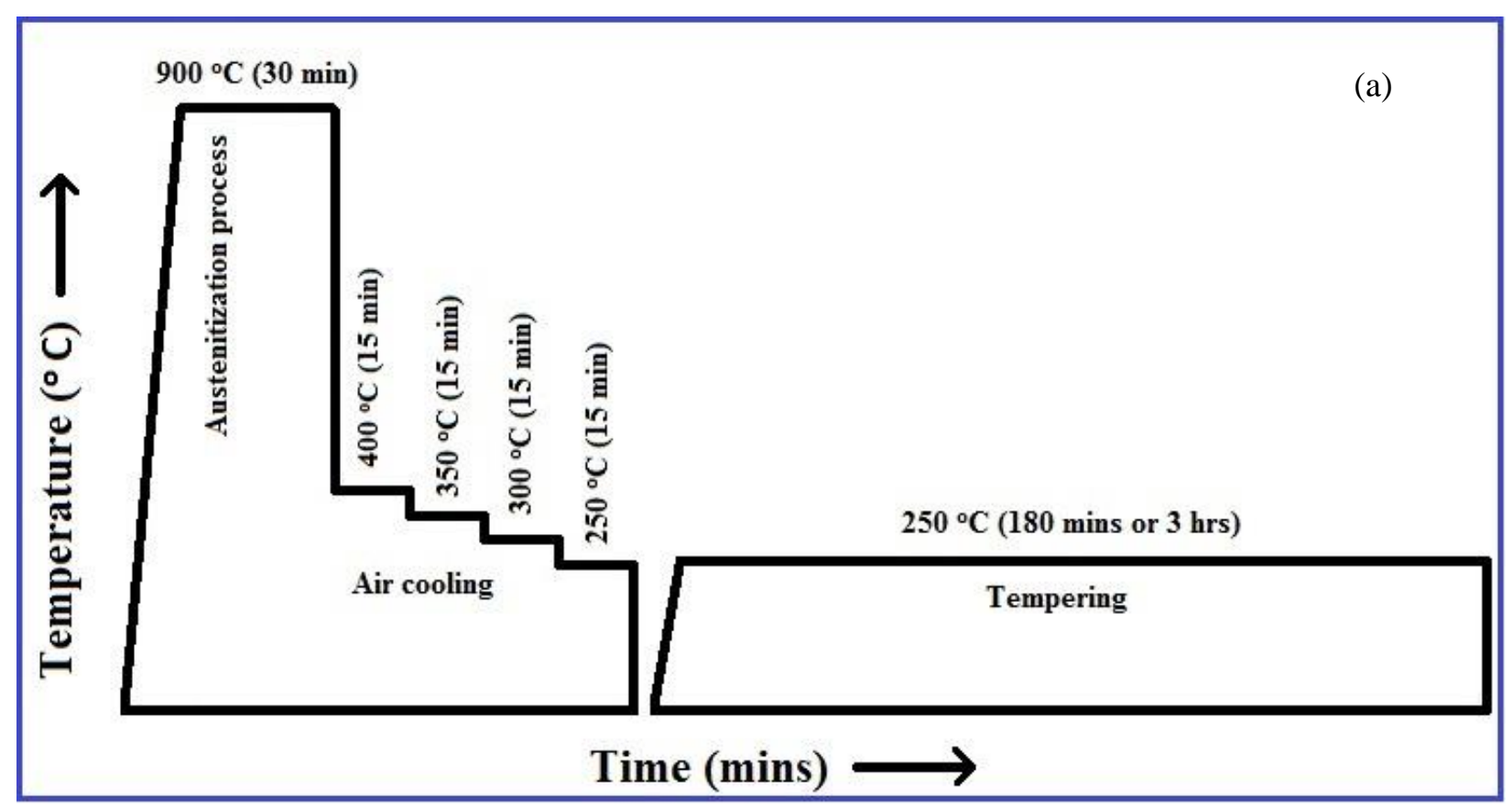




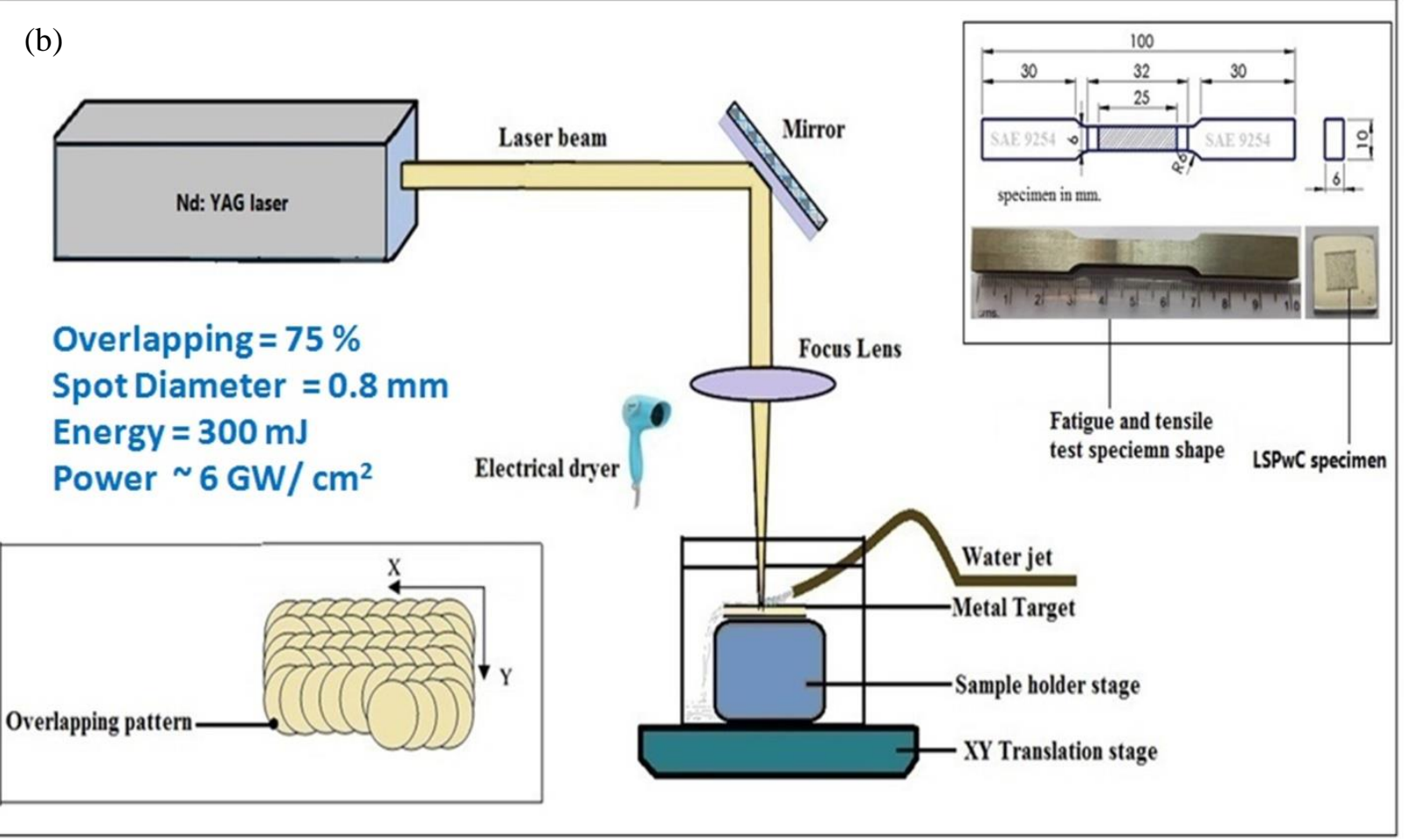

(c)

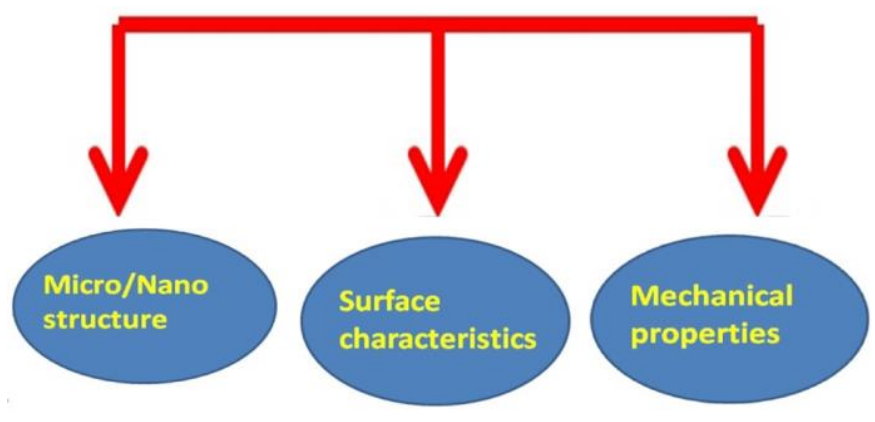

Fig.1 Schematic representations of (a) heat treatment procedure (b)LSPwC processing setup and (c)methodology of investigations

\subsection{Characterization methods}

The surface and sub-surface (upto $900 \mu \mathrm{m}$ ) residual stresses measured according to the $\sin ^{2} \Psi$ method. X-ray irradiations of $4 \mathrm{~mm}^{2}$ at the diffractive plane of (110) measured (X'pert Pro

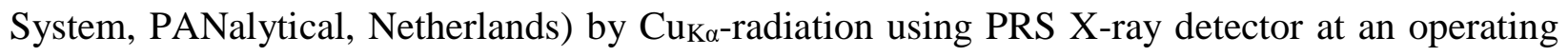
voltage of $45 \mathrm{kV}$ and current of $40 \mathrm{~mA}$. An electropolishing layer removal technique utilised for sub-surface compressive residual stress measurements via using 80\% methanol and 20\% perchloric acid mixture solution by controlling the voltage $(18 \mathrm{~V})$ with constant electropolishing 
time. The slow scan high-resolution X-ray diffraction (HR-XRD) recorded for the specimens of Bragg angle in the range from $35^{0}$ to $45^{0}$ with a step size of $0.01^{0}$. The surface roughness of the specimens was measured using a stylus profilometer (MarSurf, Germany). It is measured in contact mode, regions along longitudinal and transverse directions using roughness filter cut off $0.8 \mathrm{~mm}$ by moving the profile to $5.6 \mathrm{~mm}$. An optical microscope (Carl Zeiss) and Field emission scanning electron microscope (FE-SEM, Carl Zeiss Ultra-55) used to study the microstructure of laser treated specimen by the etchant of Nital 5\%. A high-resolution transmission electron microscope (HR-TEM, FEI, Tecnai-G $\mathrm{G}^{2} 20$, Netherlands) operating at $200 \mathrm{kV}$ is utilized to study the microstructural properties. The surface $(\sim 100 \mu \mathrm{m})$ transmission electron microscope samples were prepared using precision ion polishing system. Immense care was taken to prepare a thin foil of $100 \mu \mathrm{m}$ thickness to study the micro/nanostructures. Vickers microhardness test was conducted according to ASTM E-384 with (Matsuzawa MMT-X, micro diamond indenter) an indenting load of $1.96 \mathrm{~N}$ for a dwell time of $10 \mathrm{~s}$; readings were taken with the stepping of $50 \mu \mathrm{m}$ for five times in order to increase the precision of results. The nanoindentation (TI-900, Hysitron Inc Minneapolis, USA) measurements are carried out by a Berkovich indenter to analyze the nanomechanical properties. The fatigue tests are performed using ASTM: E8/E8M Standard test methods by a universal material testing (UTM) servo-hydraulic machine (INSTRON 8801). The fully reverse conditioned dynamic loading cyclic fatigue tests accomplished in room temperature conditions and the dynamic load of compressive and tensile stress at a frequency of $10 \mathrm{~Hz}$ and its average mean stress is fixed to be zero. The double side LSPwC was carried out for the fatigue testing specimens. Scanning electron microscope (SEM, ZEISS EVO 18, Germany) with energy dispersive spectrometer (EDS) used for the fatigue fracture morphology analysis.

Table-2: LSPwC process parameters for SAE 9254 bainitic spring steel

\begin{tabular}{|l|l|l|l|}
\hline Pulse energy & $300 \mathrm{~mJ}$ & $\begin{array}{l}\text { Hugoniot elastic } \\
\text { limit (HEL) }\end{array}$ & $\sim 2.6 \mathrm{GPa}$ \\
\hline Pulse duration & $10 \mathrm{~ns}$ & Laser wavelength & $1064 \mathrm{~nm}$ \\
\hline Repetition rate & $10 \mathrm{~Hz}$ & Spot diameter & $0.8 \mathrm{~mm}$ \\
\hline Power density & $5.97 \mathrm{GW} / \mathrm{cm}^{-2}$ & Overlapping & $75 \%$ (optimized) \\
\hline
\end{tabular}

\section{Results}




\subsection{Laser pulse density (overlapping) optimisation}

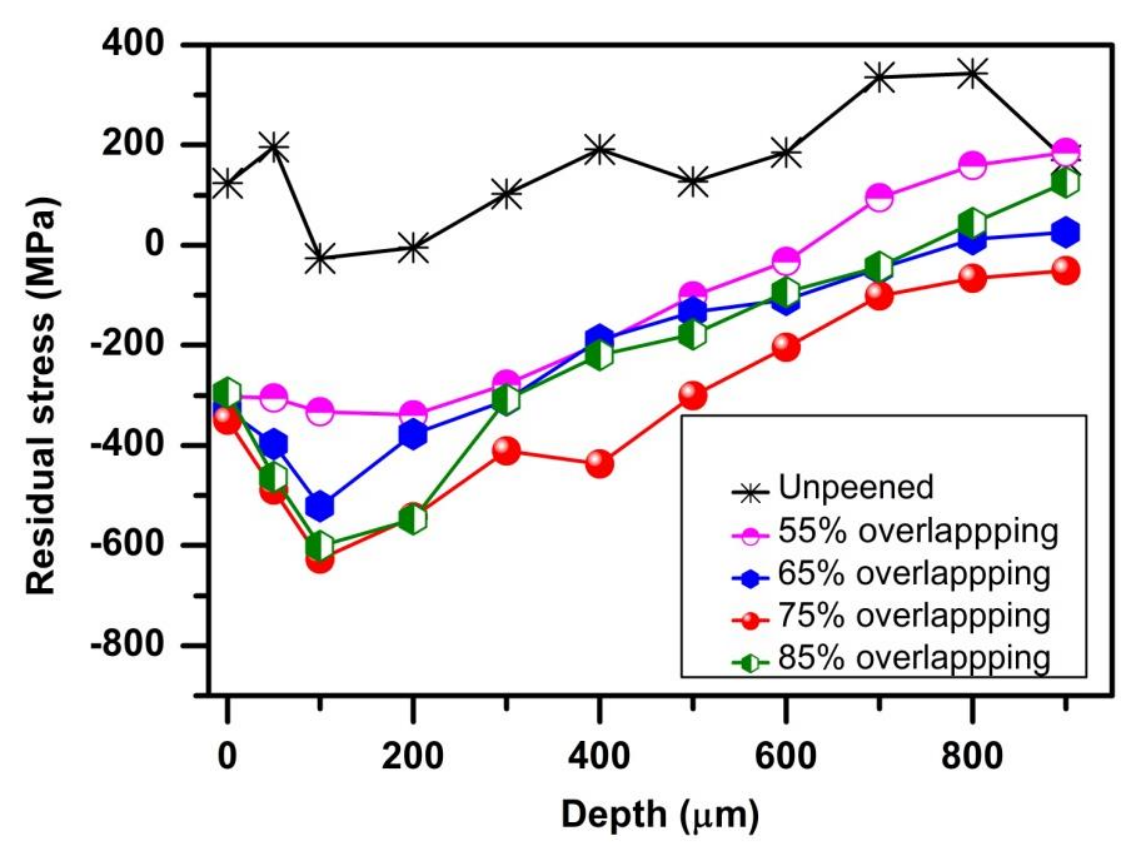

Fig.2 Residual stress depth profile of unpeened and LSPwC specimens with different laser pulse overlapping (55\% overlapping - 800 pulses $/ \mathrm{cm}^{2} ; 65 \%$ overlapping -1600 pulses $\left./ \mathrm{cm}^{2}\right) ; 75 \%$ overlapping - 2500 pulses $/ \mathrm{cm}^{2} ; 85 \%$ overlapping - 3900 pulses $\left./ \mathrm{cm}^{2}\right)$ Avg. standard deviation = $\pm 14.6 \mathrm{MPa}$

The depth profile of residual stress results of specimens treated with different pulse densities or overlappings shown in Fig.2. There is no thermal effect until the pulse density reaches 2500 pulses $/ \mathrm{cm}^{2}$, but after 2500 pulses $/ \mathrm{cm}^{2}$ the thermal effect comes into existence and there is a thermal relaxation of the stresses. As a result of the thermal effect, a part of compressive residual stresses lost, and hence the compressive residual stress value decreases at pulse density of 3900 pulses $/ \mathrm{cm}^{2}$. A layer of water is present, so the local thermal effect was not present until pulse density reaches 2500 pulses $/ \mathrm{cm}^{2}$. So, the laser pulse density of 2500 pulses $/ \mathrm{cm}^{2}$ was optimised for the further to study the surface, microstructure and mechanical characterisations of low energy LSPwC specimens.

\subsection{Phase determination}



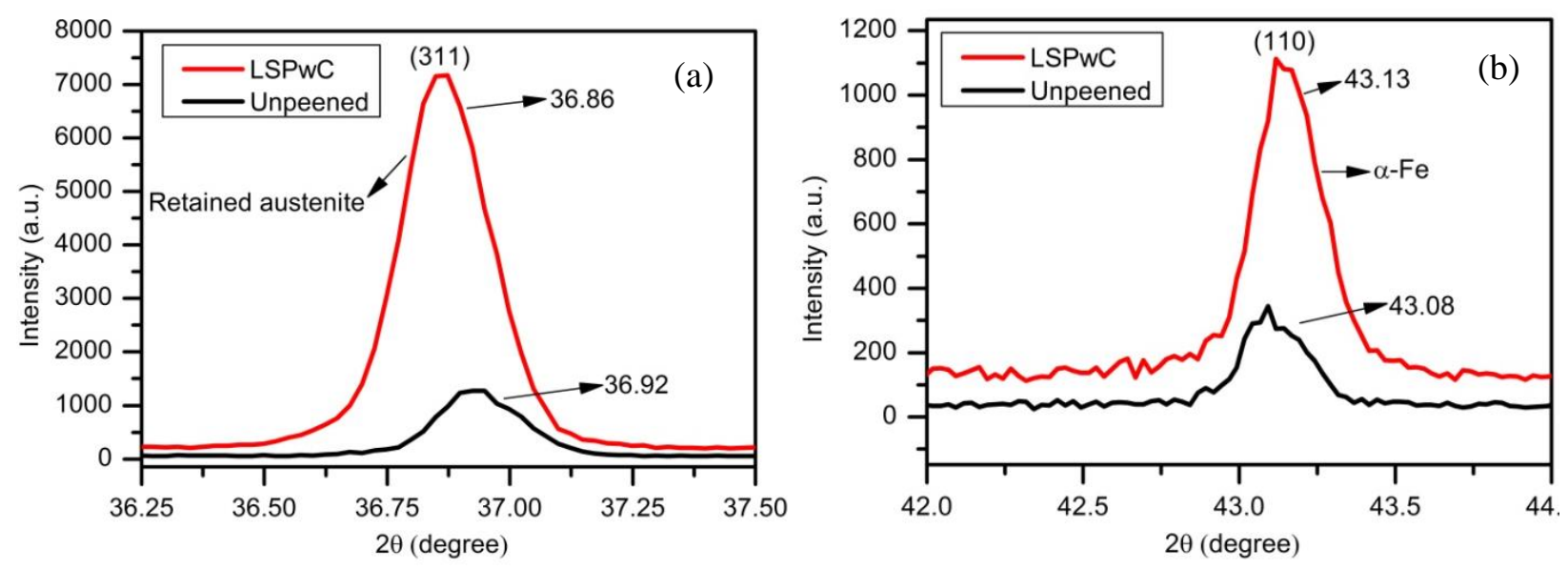

Fig.3 High-resolution X-ray diffraction of unpeened and LSPwC processed SAE 9254 spring steel

The Fig.3a discloses that there is an existence of retained austenite (FCC) in both unpeened and LSPwC specimens which are evident from the peak plane (311) at the angle around $37^{\circ}$. The peak plane (110) at the angle around $43^{\circ}$ indicates the presence of $\alpha$ - ferrites (BCC) in Fig.3b [10][19]. After performing LSPwC, the peak shift (36.92 ${ }^{\circ}$ to 36.86$)^{\circ}$ towards the lower angle in the retained austenite peak can be observed in Fig.3a and, it indicates that there is a misorientation taking place in the crystalline structure. While there is a shift in the peak $\left(43.08^{\circ}\right.$ to $43.13^{\circ}$ ) towards the higher angle is observed in case of ferrite (BCC) indicating towards a martensite (BCT) transformation (Fig.3b) i.e.,, towards $\alpha$ - martensitic ferrite from $\alpha$ - bainitic ferrite. The grain size of the crystalline material can be calculated quantitatively using the Debye Scherer's formula [20]

$$
D=\frac{0.94 \lambda}{\beta \cos \theta}(m)
$$

where $\mathrm{D}$ is the grain size of the material, $\lambda$ is the wavelength of $\mathrm{X}$-Ray used $\left(1.54 \times 10^{-10} \mathrm{~m}\right), \beta$ is the broadening of diffraction line (FWHM), and $\theta$ is the angle of diffraction.

The formula gives dislocation density,

$$
\delta=\frac{1}{D^{2}} \quad\left(\text { lines } / m^{2}\right)
$$


Here $\delta$ is the dislocation density and D is the grain size (calculated from Scherrer's formula), and the formula gives the microstrains in the grain which was induced by the LSPwC process,

$$
\varepsilon=\frac{\beta \cos \theta}{4} \quad\left(\text { lines }^{-2} / \mathrm{m}^{-4}\right)
$$

The average dislocation density ( $\delta$ ) of the unpeened and LSPwC specimens are found to be $2.584 \times 10^{18}$ lines $/ \mathrm{m}^{2}$ and $3.014 \times 10^{18}$ lines $/ \mathrm{m}^{2}$ respectively. The microstrain in the unpeened and LSPwC specimens found to be $580 \times 10^{-4}$ and $670 \times 10^{-4}$ respectively.

\subsection{Surface and roughness examinations}

Table 3: Average surface roughness $\left(\mathrm{R}_{\mathrm{a}}\right)$ of unpeened and LSPwC specimens

\begin{tabular}{lllll}
\hline Specimen & $\mathrm{R}_{\mathrm{a}}(\mu \mathrm{m})$ & $\mathrm{R}_{\mathrm{a}}(\mu \mathrm{m})$ & $\mathrm{R}_{\mathrm{a}}(\mu \mathrm{m})$ & $\mathrm{R}_{\mathrm{a}}(\mu \mathrm{m})$ \\
& location 1 & location 2 & location 3 & Average
\end{tabular}

Table 4:

$\begin{array}{lllll}\text { Unpeened } & 0.4225 & 0.5624 & 0.4912 & 0.4920 \\ \text { LSPwC } & 2.0505 & 2.4967 & 2.3943 & 2.3138\end{array}$

AFM 3-D topographic results of unpeened and $L S P w C$ specimens

\begin{tabular}{cccc}
\hline Specimen & $\mathrm{S}_{\mathrm{a}}(\mathrm{nm})$ & $\mathrm{S}_{\mathrm{p}}(\mathrm{nm})$ & $\mathrm{S}_{\mathrm{v}}(\mathrm{nm})$ \\
Unpeened & 6.5308 & 34.371 & -28.762 \\
LSPwC & 69.939 & 242.98 & -306.97 \\
\hline i.e., Sa (average height); & Sp (maximum peak height); Sv (maximum valley depth)
\end{tabular}




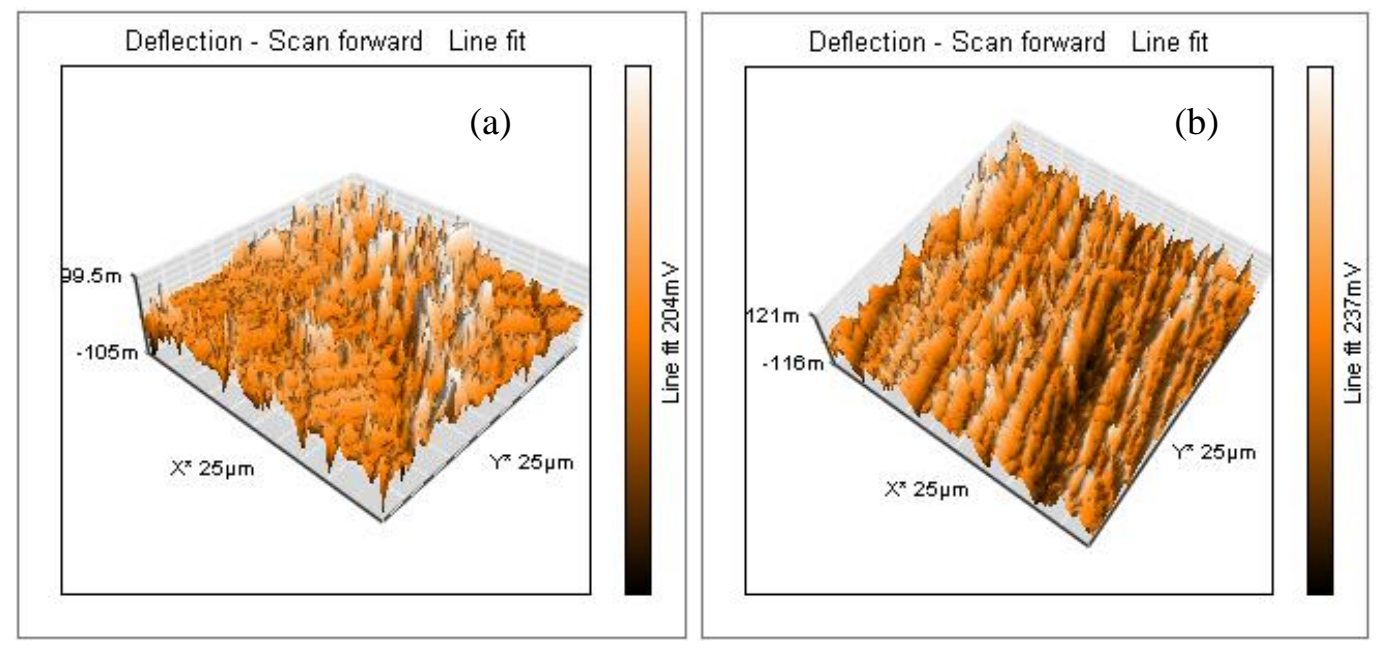

Fig.4 Atomic force microscopic 3-D topography of (a) Unpeened and (b) LSPwC specimens

The surface average roughness $(\mathrm{Ra})$ value of the unpeened and LSPwC specimens were measured, and the results with the variance are given in Table-3. The surface average roughness value of the LSPwC specimen exists an average of $2.313 \mu \mathrm{m}$ and the unpeened specimen shows an average of $0.492 \mu \mathrm{m}$. The 3D surface topography was analyzed using an atomic force microscope (AFM) (Nanosurf EasyScan 2, Switzerland) with the length of $450 \mu \mathrm{m}$, the width of $45 \mu \mathrm{m}$, tip height of $12 \mu \mathrm{m}$, the thickness of $1.5 \mu \mathrm{m}$, spring constant of $0.15 \mathrm{Nm}^{-1}$ and vertical resolution of $0.2 \mathrm{~nm}$. Surface topography of the unpeened and LSPwC samples was recorded using atomic force microscope (AFM). Figs. 4a \& 4b show the 3D surface topography of the unpeened and LSPwC samples. The results have been summarized in Table-4 taking into consideration a particular test area and the following parameters: 1. Sa (average height) 2. Sp (maximum peak height) 3. Sv (maximum valley depth).

\subsection{Micro/nanostructure investigations}
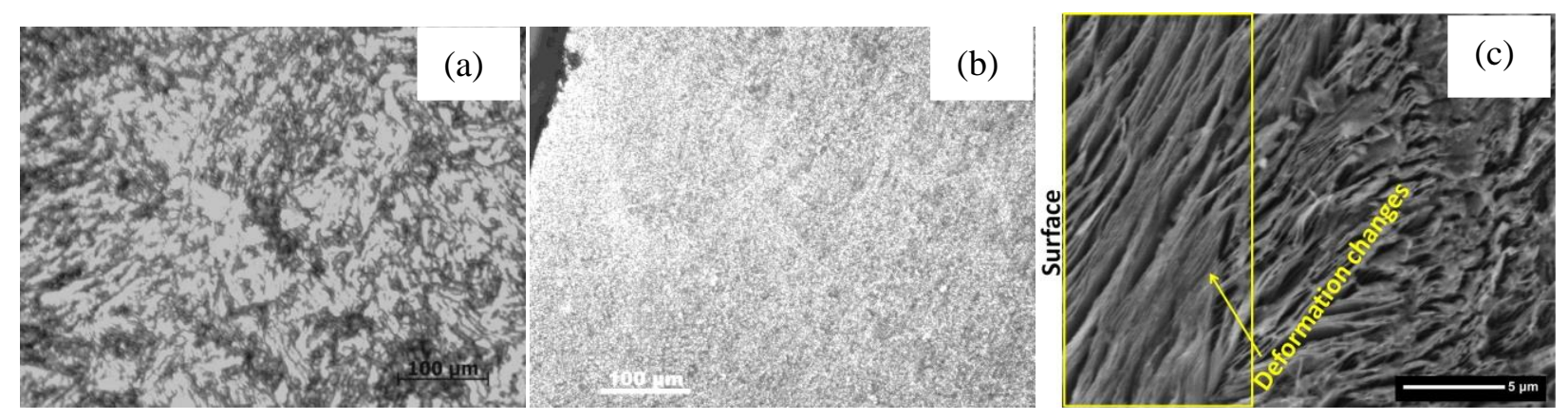
Fig.5 Optical microscopic images of (a) Unpeened and (b) LSPwC specimen and (c)FE-SEM cross-sectional near surface microstructural changes in LSPwC specimen (Etchant: 5\% of Nital \& scale bar:5 $\mu \mathrm{m})$
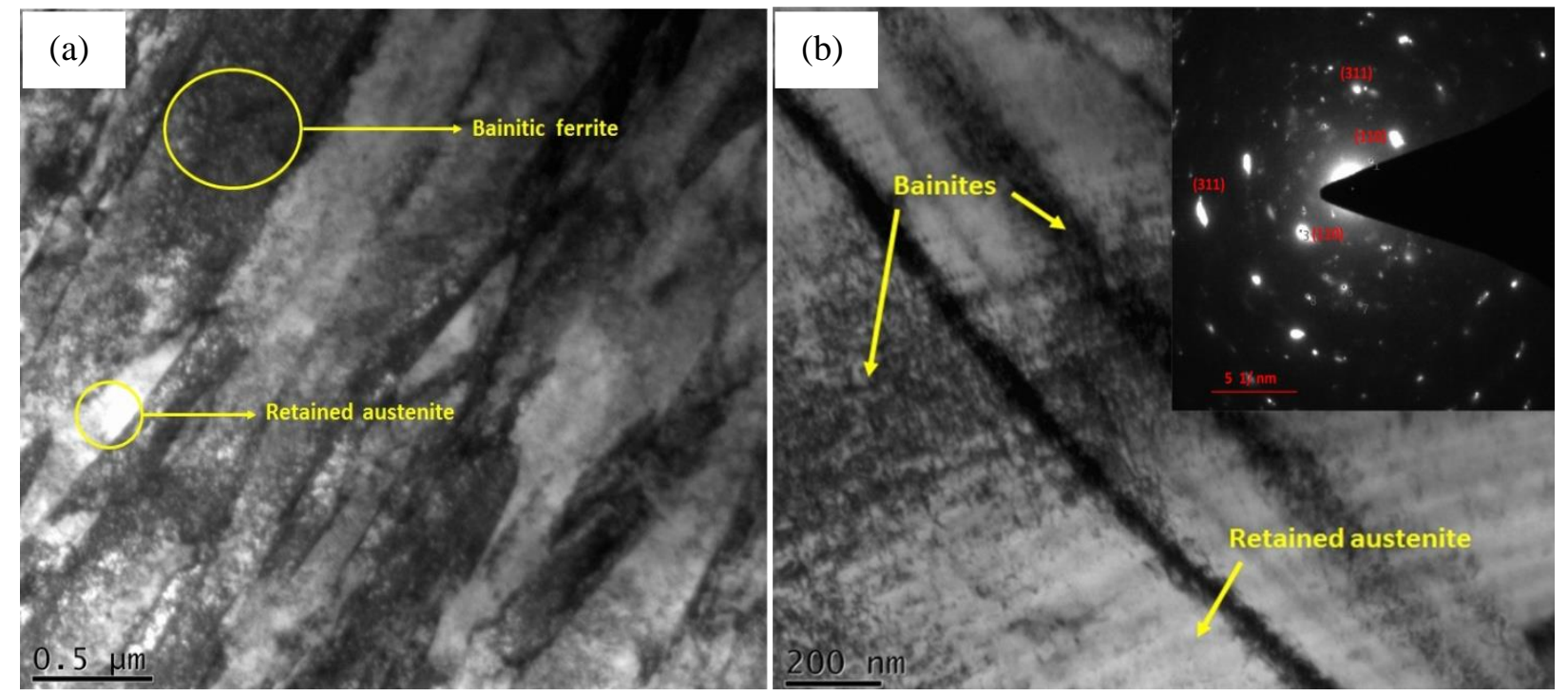

Fig.6 TEM images of unpeened specimen (Fig.6b inset image shows the corresponding selected area electron diffraction pattern) 

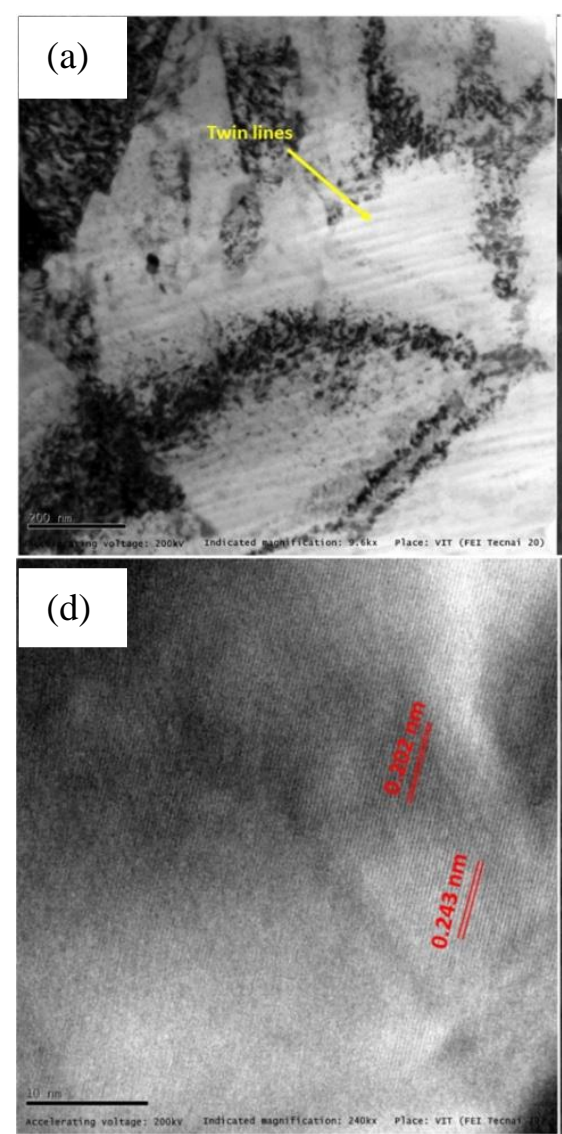

(b)

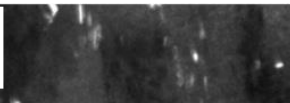

(c)
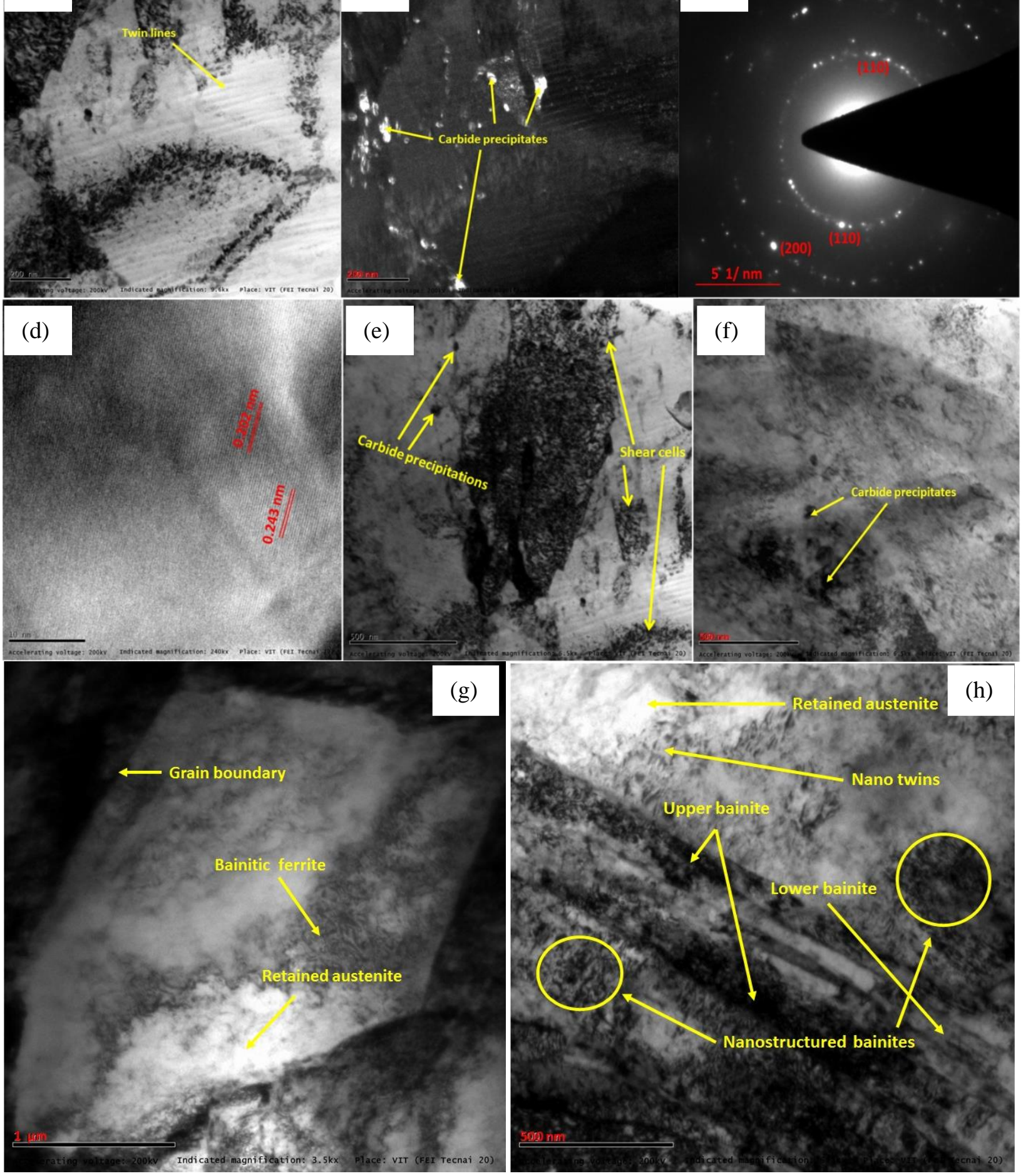


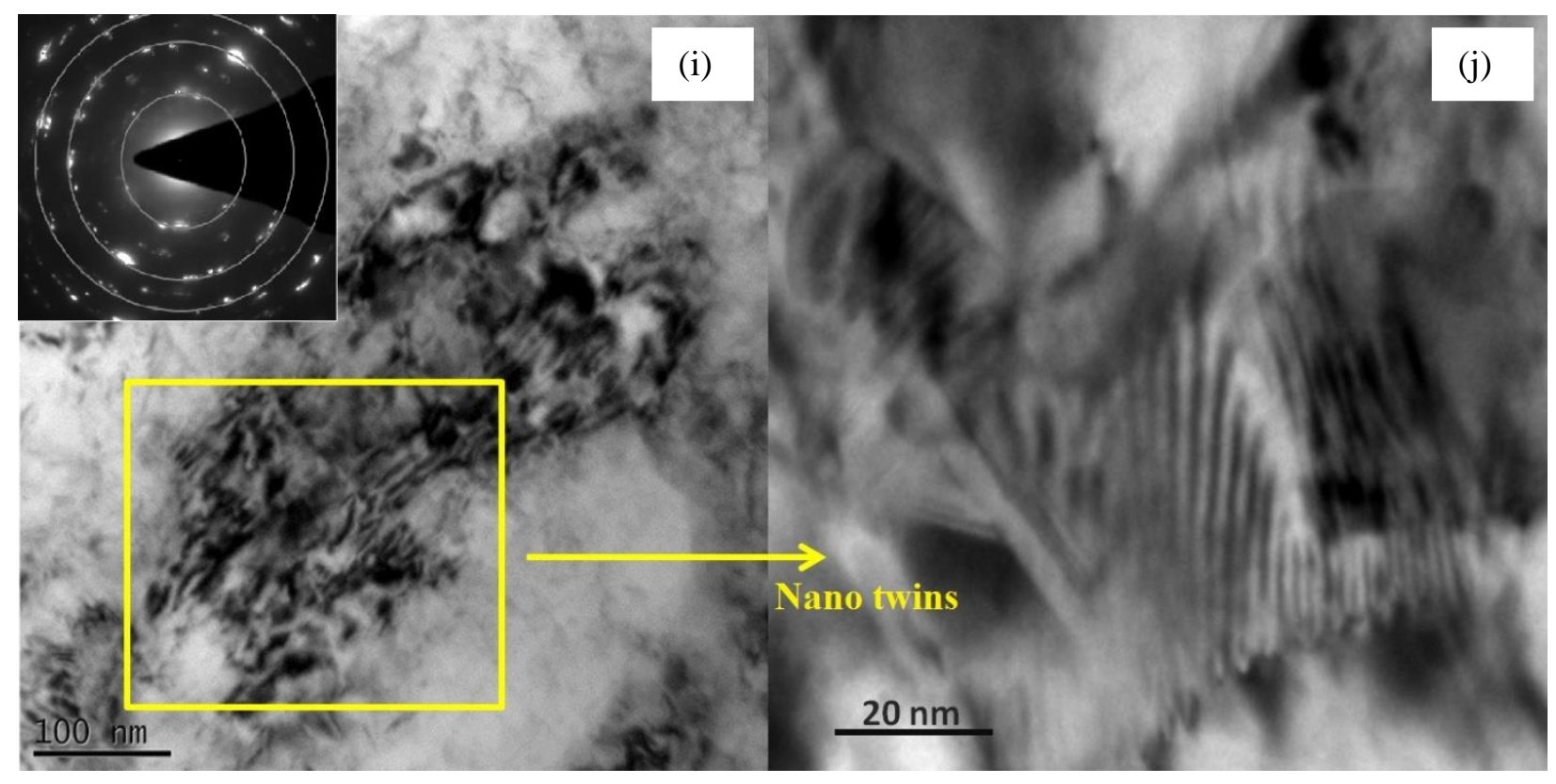

Fig.7 TEM images of LSPwC specimen (Fig.7b is corresponding dark field image of Fig.7a, and Fig. $7 g$ and inset image of Fig.7i shows the selected area electron diffraction pattern)

The optical microstructure of unpeened cross-sectional specimen is showing lath type bainitic ferrite microstructure in Fig.5a. The cross-sectional LSPwC specimen shows the grain refined major plastic deformation region by the laser shock wave induced high strain in Fig.5b. Although there were no apparent changes were observed in the microstructure from the surface in optical microscopy. The FE-SEM near surface plastic deformation changes were shown in Fig.5c. The major plastic deformations were observed upto 10-15 microns from the surface. The acicular (needle-like) bainitic structural changes on the surface are evident of LSPwC induced strains. Fig.6a\&6b reveals the presence of bainitic ferrite and retained austenite from the TEM micrograph. In addition, the inset figure in Fig.6b showing the selected area electron diffraction pattern of the unpeened specimen which is also revealed the existence of bainitic ferrite plane (110) and retained austenite plane (311). Fig.7 micrographs revealed the various nanostructured grain refinement features of the LSPwC specimen.

\subsection{Hardness measurements}



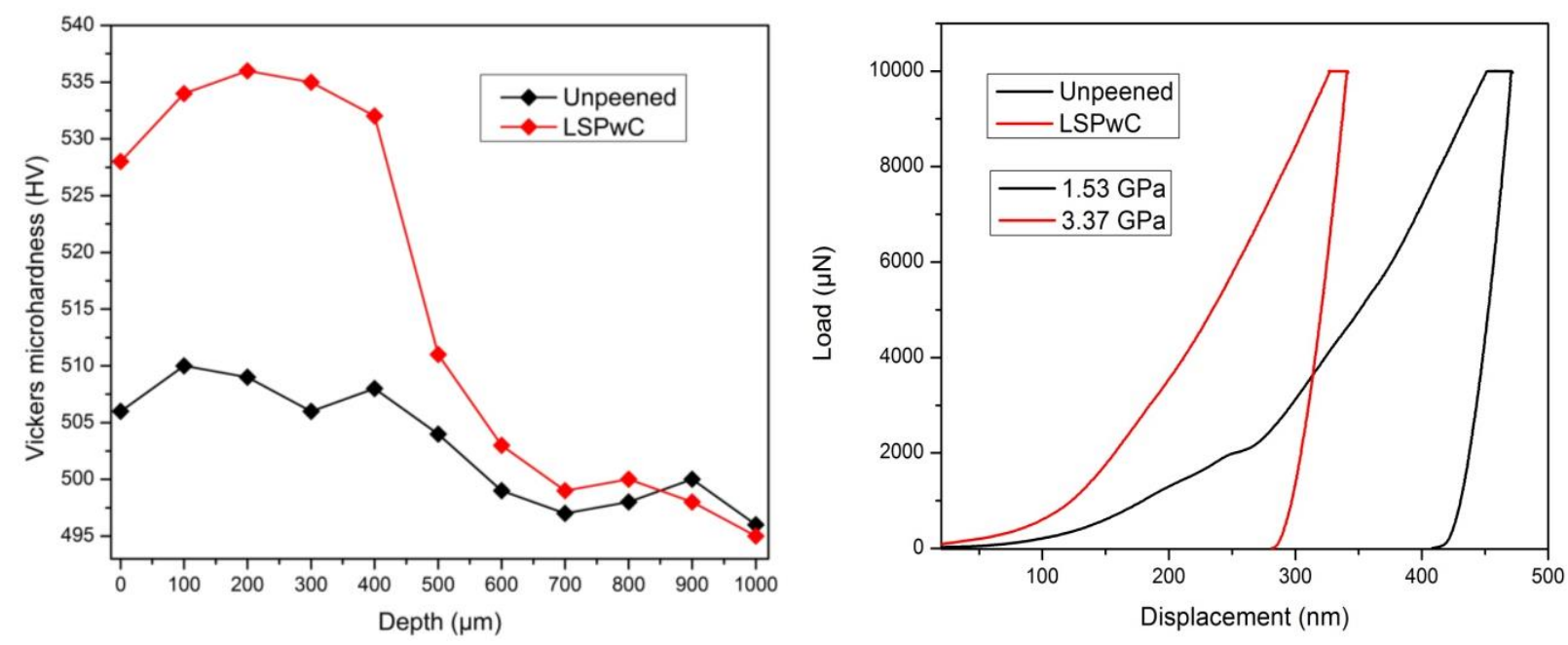

Fig.8 (a) Vickers microhardness depth profile [Avg. standard deviation $= \pm 9.4 \mathrm{HV}$ ] and, $(\mathrm{c})$ nanoindentation profile of SAE 9254 bainitic spring steel

The hardness profile obtained from Vickers microhardness test as a function of depth is shown in Fig 8a. The test performed for five times and an average of these is taken into consideration for the precision and clarity of discussion. The LSPwC specimen exhibits improved hardness values up to the depth of 800 microns. The average original surface microhardness of the unpeened and the LSPwC specimens was calculated to be $506.8 \mathrm{HV}$ and 529.3 HV respectively. For the ultrafine grains, nano-hardness is a more reliable approach as compared to microhardness. Also, an advantage is the indentation can be marked on the grains without falling on the boundary lines. So it is easy to know the definite improvement achieved by the LSPwC process. The nano-hardness $(\mathrm{H})$ can be defined by [11]

$$
H=\frac{P_{\max }}{A}
$$

Where ' $\mathrm{A}$ ' is the concentrated area of contact, and ' $\mathrm{P}_{\max }$ ' is the maximum force applied. Energy spent during plastic deformation is the product of maximum applied force and the maximum displacement. The values considered for the discussion is an average of five indentations for the precision and clarity. The load vs depth displacement of the nanoindentation test is carried out for the unpeened and LSPwC specimens and result profile shown in Fig.8b. The nano-hardness for unpeened specimen exhibits $1.53 \mathrm{GPa}$, and it noticeably increased in the LSPwC specimen to 3.37 GPa. The value is found to be increased by approximately $120 \%$ after the LSPwC process 
was carried out. The reduced elastic modulus and stiffness values also showed significant improvement after LSPwC. The energy spent for plastic deformation values indicated the increased plastic nature of the LSPwC specimen shown in Table 5.

The following equation gives the Hugoniot elastic limit [12][14],

$$
H E L=\frac{1-v}{1-2 v} \sigma_{y}^{d y n}
$$

Where the dynamic yield strength is provided by $\sigma_{y}^{d y n}$, and Poisson's ratio by ' $v$ '.

Table 5: Results for nanomechanical properties of SAE 9254 spring steel

\begin{tabular}{llc}
\hline Properties & Unpeened & LSPwC \\
Reduced Modulus $(\mathrm{GPa})$ & 107.19 & 148.93 \\
Stiffness $(\mu \mathrm{N} / \mathrm{nm})$ & 308.06 & 291.29 \\
Nano-hardness $(\mathrm{GPa})$ & 1.53 & 3.37 \\
Energy spent in plastic deformation, $\mathrm{W}_{\mathrm{p}}\left(\times 10^{-9}\right) \mathrm{N} \mathrm{m}$ & 4.72 & 3.21 \\
\hline
\end{tabular}

\section{$3 . 6 \longdiv { \text { High-cycle fatigue studies } }$}

Table 6: The fully-reversed $(R=-1)$ fatigue test results of SAE 9254 bainitic spring steel

\begin{tabular}{|c|c|c|c|c|c|}
\hline $\begin{array}{c}\text { Specimen Manufacturing } \\
\text { Process }\end{array}$ & $\begin{array}{c}\text { Fatigue } \\
\text { load } \\
(\mathrm{kN})\end{array}$ & $\begin{array}{c}\text { Fatigue life } \\
\left(\times 10^{5} \text { cycles }\right) \\
\text { Specimen } 1\end{array}$ & $\begin{array}{l}\text { Fatigue life } \\
\left(\times 10^{5} \text { cycles }\right) \\
\text { Specimen } 2\end{array}$ & $\begin{array}{c}\text { Fatigue life } \\
\left(\times 10^{5} \text { cycles }\right) \\
\text { Specimen } 3\end{array}$ & $\begin{array}{c}\text { Average } \\
\text { Fatigue life } \\
\left(\times 10^{5} \text { cycles }\right)\end{array}$ \\
\hline Unpeened & 8 & 2.74 & 3.48 & 2.99 & 3.07 \\
\hline LSPwC & 8 & 16.73 & 20.14 & 18.26 & 18.37 \\
\hline $50 \%$ pre-fatigued $+\mathrm{LSPwC}$ & 8 & 9.84 & 7.26 & 9.16 & 8.75 \\
\hline
\end{tabular}

The fatigue life is mainly consisting of two periods; First, the crack initiation period occurs which is strongly dependent on the surface condition of the material. Second, the crack growth occurs which is hardly depend on surface condition, however primarily influenced by 
property of the bulk material. It is well understood that in the fatigue life of metals, the period of crack initiation is much sensitive than the crack growth period. Cyclic stress relaxation is affected mainly by the initial magnitude and gradient of the residual stress field, the degree of cold work, fatigue stress amplitude, mean stress ratio, the number of cycles, material stress-strain response and degree of cyclic work hardening or softening [9][10]. The LSPwC process can generate plastic deformation, uniquely deep and with a spot by spot placement thus enabling components to achieve compressive residual stress on a deep level.

For the automotive suspension spring parts, a fully reversed $(\mathrm{R}=-1)$ push-pull loading is most suitable to identify the effect of laser peening. Ganesh et.al.[9] has reported that higher fatigue life can be obtained by resorting to laser peening via the three-point bending fatigue test of martensite spring steel. Sano et.al.[16] reported that the LSPwC effect on titanium and stainless steels through plane bending fatigue test $(\mathrm{R}=-1)$ using low energy laser. The fully reversed $(\mathrm{R}=-1)$ tension-compression load controlled high-cycle fatigue test is carried out using dog-bone shape ASTM E-8/E8M standard specimen (dimensions are in inset Fig.1) at ambient temperature. In order to complete the studies in a reasonable time frame, the testing parameters like load $(8 \mathrm{kN})$ and frequency $(10 \mathrm{~Hz})$ are fixed in the universal material testing servo-hydraulic machine. The results in Table-6 show that the unpeened specimen withstands only up to $3.07 \times 10^{5}$ cycles, but the LSPwC specimen can withstand more than $18.37 \times 10^{5}$ cycles. The LSPwC process using low energy laser substantially increased the lifecycle of automotive spring steel by more than $83.29 \%$. The tests are repeated three times to confirm the results and to increase the degree of precision. The Table-6 showed the observations about that specimen which is first $50 \%$ pre-fatigued, and then LSPwC is applied over the surface and then again remaining $50 \%$ fatigue cycles were applied. This observation also proves that even a specimen is initially affected by pre-fatigue can be able to withstand more than $8.75 \times 10^{5}$ cycles which are more than the unpeened sample. The fatigue life of the specimen after LSPwC is comparatively improved with the previous studies reported by Ganesh et.al.[9] and Prabhakaran and Kalainathan[10]. The fracture morphology of unpeened fatigue tested specimens were evaluated, and the fatigue failure occurred or initiated from the corrosion pits in a few cases during the study. The unpeened fatigue tested specimens showed macro voids, cracks and small dimples (Fig.S1a\&b). In the case of fatigue tested LSPwC specimen (Fig.S2a\&b) showed only small voids and dimples. Fig.S3. illustrates the elemental mapping of all the composition of the 
specimen. Elemental mapping is the high-resolution images from a scanning electron microscope (SEM) and elemental spectral data gained using EDS can be combined to allow for an extremely detailed analysis of materials and multi-phase samples.

\section{Discussion}

\subsection{LSPwC induced residual stress analysis}

The unpeened specimen exhibits a certain amount of residual tensile stresses on the surface and its sub-surfaces. Fournier et al. [21] revealed the residual stress profiles for a pulse time of 2.5 and 25 ns utilizing different power densities on 35CD4 and XC38 steel. They [21] expressed that the mechanical impact because of shock wave relies on upon surface load and pressure time profile. Ocatia et al. [22] showed that more profundity was achieved with longer pulse time which relates to lower power density and the compressive zone was expanded when contrasted with shorter pulse time with higher power density. Ganesh et al. [9] describe the study of LSP on suspension spring steel for automotive applications. Springs, in general, are meant to absorb, store and then release the energy, hence the strain energy of the material appropriately a major factor in designing the springs. The specific strain energy can be expressed as

$$
U=\frac{\sigma^{2}}{\rho E}
$$

Where $\sigma$ is the strength, $\rho$ is the density and E is Young's modulus of spring material. The presence of the tensile residual stresses can be explained it was due to the sample preparation methods and the deformations produced during hot rolling. After the application of LSPwC with variable pulse densities, it is observed that the surface compressive residual stress is comparatively less than the sub-surface value. This can be explained owing to the direct laser ablation on the surface of the material [12]. As evident from the Fig.2, the magnitude of compressive residual stress varies linearly with pulse density upto $2500 \mathrm{pulses} / \mathrm{cm}^{2}$. At the pulse density of $2500 \mathrm{pulses} / \mathrm{cm}^{2}$, the compressive residual stress values attain a maximum point and then start to reduce. The value of compressive residual stress goes on decreasing slowly as we go further away from the $100 \mu \mathrm{m}$ sub-surface layer for all the processed laser pulse densities. This phenomenon occurs because the intensity of the shock waves is the maximum at near surface layer and it dwindles as it propagates further into the material. Apart from these interesting 
behaviors, LSPwC technique using low energy laser demonstrated as a promising technique to induce high magnitude of compressive residual stresses. The induced residual stress for the single pass LSPwC signifies that it is higher than the author's previous report [11].

\subsection{Phase analysis}

Further, the resulting peak shift trend in Fig.3 depicts that the current process is inducing the misorientation or martensite phase transformation trend in the crystalline structure. Likewise, the elevated intensity of the peak indicates that residual stress has been actuated in the specimen after the LSPwC process. Xie Zhang et.al [23] has explained the atomistic process of structural phase transitions of austenite (face centred cubic) and ferrite (body centred cubic) structures through ab initio simulations. The compressive residual stress induced during the LSPwC process causes the d-spacing of the crystal structure to change, thus causing it to align the plane in such a way that it gives maximum intensity [12]. After LSPwC process, there is a plastic deformation generated in the specimen by the laser shock wave induced strain. Amid the plastic deformation, the dislocations are generated via Frank-Read sources thus leading to increase in the dislocation density [24]. The Frank-Read [25] source explains the formation of multiple dislocations in particular slip planes of crystal when the crystal is deformed. The phase transformation trend and misorientation in the crystalline structure through single pass LSPwC at the room temperature is a significant response observed from the current experiment. Because, there was no phase changes observed with the dual-phase structured steel even after five passes of LSPwC in our previous report [11].

\subsection{Surface roughness and AFM 3D topography analysis}

The increase in the surface roughness of LSPwC treated specimens can be explained owing to the direct laser ablation process taking place on the metal surface. The value of surface roughness is affected by the following factors: a) Laser pulse energy b) Overlapping rate c) Laser shock peening time. The peak pressure induced by laser ablation increases with increasing energy of the laser pulse, but in the present study, the laser energy is limited to $300 \mathrm{~mJ}$. Because this affects the profundity and the amount to which stresses induced on the surface of the specimen. The current process controlled the induction of excess amount of surface roughness and provided to maintain the good surface quality by inducing maximum compressive residual 
stress which will support to improve the corrosion and fatigue properties of the specimen, and it is consistent in the literature. The laser ablation material removal rate was calculated to be $\sim 1.2$ $\mu \mathrm{m}$ for the nanosecond LSPwC process. Further, it is worth enough to compare based on surface finish through AFM results, and it coincidence with the calculated value of $\pm 0.5 \mu \mathrm{m}$ [26]. So, the study claimed that the single pass LSPwC technique can able to control the excessive surface roughness induction and it is reduced from four to eight times than the conventional shot peening technique $[11][12][14]$.

\subsection{Micro/nanostructure analysis}

Upper bainite is formed at a transformation temperature of around $450^{\circ} \mathrm{C}$ while the lower bainite structure is formed around $250^{\circ} \mathrm{C}$. Low carbon diffusion rate is responsible for the formation of lower bainites. The carbon diffusion rate is low because, the temperature at which lower bainite transformation prevails is low in the first place. In case of upper bainites, carbon diffuses into austenite as the diffusion rate is fast and the temperature is high, whereas in case of lower bainite the carbon diffuses into austenite as well as precipitates in ferrite as shown in the Fig.S4. The rate-controlling element for the evolution of upper bainite is the diffusion of carbon in austenite. Whereas the diffusion of carbon in supersaturated ferrite is proposed to be the rate controlling factor for the development of lower bainitic ferrites. The formation process of upper and lower bainitic ferrites has been illustrated in Fig.S4 [1][3][27].

The Fig.7a is a bright field TEM micrograph showing the formation of twin lines. These twin lines were formed due to the high strain produced as a consequence of the LSPwC process [11][27]. Whereas, in Fig.7b shows the dark field image of the TEM micrograph as Fig.7a. The carbide nanoprecipitates can be evidently seen in Fig.7b, and these carbide nanoprecipitates are produced during heat treatment, and it is highly strain induced after LSPwC. Further, in Fig.7a and Fig. 7b, it was observed that the precipitations were formed at the grain boundaries. Also, the precipitation grows denser; it will hinder the dislocation slip movement caused by the LSPwC process. And it will lead to higher dislocation density of the material. The size of the distribution of the precipitations lies in the range of 5-15 nm. Further, the selected area electron diffraction of LSPwC specimen in Fig.7c shows the presence of ferritic planes (110) and (200), and in this case, the retained austenite plane was not observed clearly, and this may be another evidence for the martensite phase transformation trend taking place after LSPwC treatment. The martensite 
phase transformation will soften the grains, and it leads to increase the surface hardness. Fig.7d shows the d-spacing between the crystalline planes in the structure and the average $d$-spacing for the LSPwC specimen calculated to be $0.213 \mathrm{~nm}$. In the case of the unpeened specimen, the calculated average d-spacing is to be $0.547 \mathrm{~nm}$.

Due to the induction of high-pressure shock wave in LSPwC, there may be a reduction in the stacking fault energy (SFE) of the material [11]. The reduction in SFE results in highly dense dislocations in the material which accumulate resulting in deformation twinning in the material. Dislocations and some of the microstructure refinement features viz. micro shear structures (shear cells) have been observed in Fig.7e due to high strain-induced deformation by the LSPwC process. The finer carbide precipitations were observed in the dislocation region which will increase the dislocation density Fig.7f [28][29]. The dislocation results in refined grain sizes thereby improved the strength of the material which can be explained by Hall-Petch equation [30],

$$
\sigma_{y}=\sigma_{0}+\frac{k_{y}}{\sqrt{d}}
$$

Where $\sigma_{\mathrm{y}}$ is the yield stress, $\sigma_{\mathrm{o}}$ is the material's constant, $\mathrm{k}_{\mathrm{y}}$ is the strengthening coefficient, and $\mathrm{d}$ is the average grain diameter. The yield strength of the untreated and LSPwC specimens is calculated to be 204.9 $\mathrm{MPa}$ and 216.4 MPa respectively, and the average grain diameter was taken from the micrograph analysis. This strengthening of the material arises due to dislocation and dislocation movements within the crystal structure. Dislocation lines move across other dislocations. As further, deformation of the material takes place more and more dislocations start slipping into the material from different directions into the different slip planes. The interactions between dislocations and the different directions increase as the deformation continues, whereas the free area where the deformations can slip goes on narrowing down. This hardens the material, and the phenomenon is known as work/strain hardening effect [12]. The shear inconsistencies (bands) that are created at high strain rates significantly influence the microstructure inside the shear restriction area [31][32]. The Fig.7g shows the presence of bainitic and retained austenite phases in the coarse grain and grain boundaries of the LSPwC micrograph. In the Fig.7h some traces of retained austenite are visible, and there is the formation of nanostructured bainite. The nanostructured bainite is formed due to severe plastic deformation 
which is caused due to LSPwC process. The upper and lower bainitic structures can also be evident from the TEM micrograph. Also, Fig.7h unveils the existence of nucleating nanotwins and the high-resolution TEM micrographs in Fig.7i\&j also evidence for the existence of nucleating nanotwins. Nano-twins formation provides an improvement of the strength and ductility of metals [32].

\subsection{Hardness analysis}

The inhomogeneity present at the few microns of the surface of the graph is due to softening of the material at the surface due to the thermal effect caused by laser-material interaction and also due to the effect of surface roughness [11][12]. The increase in hardness values can be explained owing to the deformation twinning produced, grain refinement and the precipitates scattered at the sub-grain limits and inside the grains which hinder the movement of dislocations [12]. When deformation twinning is produced in the specimen, work hardening effect is taking place, and the hardness value of the specimen is increased. Hall-Petch relation (equation.7) gives the relationship between grain refinement and the hardness of specimen [30]. The higher hardness values were recorded up to a depth of $400 \mu \mathrm{m}$ after which it gradually started decreasing with increasing depth. The effect can be explained due to the reduction in shock wave intensity during its propagation into the depth of the material [12]. From the nanoindentation studies, the energy spent for plastic deformation of LSPwC specimen is ultimately less than the unpeened specimen, and it shows improved plastic characteristics in LSPwC treated specimens. However, these characterization techniques give researchers an insight regarding the changes and modifications due to LSPwC process. Reduced elastic modulus and nano-hardness properties are a vital role in the foreign object damage of metallic materials in aerospace and automotive industries. In contrast to a relatively hardening depth of the shot peened specimen, the LSPwC specimen hardening depth is higher [13][14].

\subsection{High-cycle fatigue test and fracture analysis}

The compressive residual stress produced during the LSPwC process causes the dislocation density to increase, thus, leading to increased dislocation movements within the crystal structure; ultimately, causing strength increase within the material. The base metal strength increases after LSPwC; it provides a significant improvement in the fatigue life of the 
specimen. Hence it is better to assume that the resistance of the specimen has increased to withstand the plastic deformation. This increased resistance to plastic deformation retards the initiation of fatigue crack nucleation at the surface of the material [33]. However, the problem is that the initial residual stress field inherent or induced in the finished product may not remain stable during the operating life of the component and residual stresses may decrease and redistribute through a process called residual stress relaxation [33][34].

The phenomenon can be explained that the compressive residual stress induced high strain to improve the hardness of the material. The reduction in the number of macro voids results in an increase of the fatigue strength, fatigue life, slower crack propagation and tensile strength in the material. The appearance of cracks from surface texture shows that stress concentrations at the surface can superimpose with residual stresses created by the LSPwC treatment. The tendency of crack generation can be observed, greater the depth of the crack source, the greater the numbers of cycles until failure [34]. All the LSPwC or unpeened specimens in the case of high cycle fatigue had their cracks originated from the surface. This fact can be explained since the high applied tension stresses always surpass the compressive residual stress force in cases of high cycle condition. In unpeened specimens, it is natural that the crack source comes from the surface, where the maximum tensile stress occurs, induced by the test characteristics. It was interesting to observe that there was a consistent gain in fatigue life in relation to the base material. It is possible to speculate about the influence of two different mechanisms acting simultaneously. In the first, the compressive stress pushes the crack source under the metal surface, and in the second the compressive stress force delays the crack propagation until failure when the crack source is at the surface [11][34]. A fractographic study of the failed specimen indicates the presence of inclusions in the subsurface (at a depth of around $250 \mu \mathrm{m}$ ) of the specimen as shown in Fig.S2b. Energy dispersive spectroscopic (EDS) analysis of the inclusions has been carried out (Fig.S2c) and dictates the presence of complex silicon, chromium and iron oxides. It is scrutinized that the fatigue crack did not initiate from this inclusions, but these inclusions will more prominently lead the fatigue failure [9]. A computerassisted analysis of the indexed data adds colour to an SEM image to correlate elements or discrete phases with individual colours of $\mathrm{C}, \mathrm{O}, \mathrm{Si}, \mathrm{Cr}, \mathrm{Fe}$ and $\mathrm{Mn}$. These results attribute evidence for the formed oxide inclusions of $\mathrm{Cr}$ and $\mathrm{Si}$ because of the presence of oxygen on the fractured surface. This is the first report on fatigue life of laser shock processed bainitic steel. So, 
comparison of fatigue life in the current literature would not contribute to the achieved overall fatigue property enhancement and intent of the study.

\section{Conclusions and future scope}

The following conclusions may be worthy to consider based on the results and discussion,

1. In present study for the first time, laser shock peening without coating (LSPwC) was implemented to investigate surface, microstructure and mechanical properties of bainitic spring steel. The experiment was successfully carried out based on the induced high compressive residual stress with an optimized laser pulse density of 2500 pulses $/ \mathrm{cm}^{2}$ (75\% overlapping).

2. The study clearly indicates the significance of laser pulse overlapping in order to induce high and deep magnitude of compressive residual stress for the mitigation of fatigue failures through novel laser shock peening without coating process.

3. The phase analysis indicated that the trend towards strain-induced martensite transformation to suggest that further multiple laser shots may bring about a full martensite transformation.

4. The microstructural grain refinement features such as twins, micro shear bands, and shear shells are evident for plastic deformation induction after laser shock peening without coating. This methodology may be useful in future to produce a nanocrystalline surface layer of bainitic steels through severe plastic deformations.

5. The laser shock peening without coating induced hardening effect was observed till the depth of $800 \mu \mathrm{m}$, and this indicated that the process has a significant effect on bulk material property enhancement. Nanoindentation studies also revealed the surface hardness enhancement attained after the LSPwC process of about $120 \%$.

6. The average fatigue life improvement was more than fifteen times that of the unpeened specimen after applying the low energy LSPwC process. As well the process is repairing the prefatigued specimen significantly and improved the fatigue life by five times than the unpeened specimen. The $\mathrm{Cr}$ and $\mathrm{Si}$ oxide inclusions were observed in the fatigue fracture morphology, which is most prominent to lead the fatigue failure.

7. This investigation is a first step towards the industrialisation of laser shock peening without coating using low energy laser. Its success will then enable one to scale the technology, make it faster, and more mobile to then serve the industries.

\section{Supplementary}




\section{A Supplementary file is attached}

\section{Patent and acknowledgement}

The authors would like to thank VIT management for the facilities and financial support to file a part of this work as an Indian patent (Application no.: 201641031003). Prof. Devendranath Ramkumar gratefully acknowledged for availing the heat treatment facilities. We also would like to thank our industrial supporters from JSW Steel Ltd, Salem works, India.

\section{References}

[1] Bhadeshia, H. K. D. H. "Steels for bearings." Progress in materials Science 57, no. 2 (2012): $268-435$.

[2] Halfa, Hossam. "Recent trends in producing ultrafine grained steels." Journal of Minerals and Materials Characterization and Engineering, 2 (2014), 428-469.

[3] Bhadeshia, H. K. D. H. "Bainite in Steels-Transformation, Microstructure and Properties." Institute of Materials, 1 Carlton House Terrace, London, SW 1 Y 5 DB, UK, 2001. 454 (2001).

[4] Cruz, J. A., T. F. M. Rodrigues, V. D. C. Viana, H. Abreu, and D. B. Santos. "Influence of temperature and time of austempering treatment on mechanical properties of SAE 9254 commercial steel." steel research international 83, no. 1 (2012): 22-31.

[5] Garcia-Mateo, C., and F. G. Caballero. "Advanced high strength bainitic steels." Comprehensive materials processing 1 (2014): 165-190.

[6] Han, Zhenyu, Ming Zou, J. I. A. Jihai, Hua Guo, Jianhua Liu, Yong Deng, W. A. N. G. Chunjian, Jun Yuan, and Hui Yao. "Method for heat-treating bainite steel rail." U.S. Patent Application 14/055,319, filed October 16, 2013.

[7] Hohenwarter, A., B. Völker, M. W. Kapp, Y. Li, S. Goto, D. Raabe, and R. Pippan. "Ultrastrong and damage tolerant metallic bulk materials: A lesson from nanostructured pearlitic steel wires." Scientific Reports 6 (2016). 
[8] Wang, Kaikai, Zhunli Tan, Guhui Gao, Bo Gao, Xiaolu Gui, R. DK Misra, and Bingzhe Bai. "Microstructure-property relationship in bainitic steel: The effect of austempering." Materials Science and Engineering: A 675 (2016): 120-127.

[9] Ganesh, P., R. Sundar, H. Kumar, R. Kaul, K. Ranganathan, P. Hedaoo, G. Raghavendra et al. "Studies on fatigue life enhancement of pre-fatigued spring steel specimens using laser shock peening." Materials \& Design (1980-2015) 54 (2014): 734-741.

[10] Prabhakaran, S., and S. Kalainathan. "Warm laser shock peening without coating induced phase transformations and pinning effect on fatigue life of low-alloy steel." Materials \& Design 107 (2016): 98-107.

[11] Prabhakaran, S., and S. Kalainathan. "Compound technology of manufacturing and multiple laser peening on microstructure and fatigue life of dual-phase spring steel." Materials Science and Engineering: A 674 (2016): 634-645.

[12] Prabhakaran, S., Aniket Kulkarni, G. Vasanth, S. Kalainathan, Pratik Shukla, and Vijay K. Vasudevan. "Laser shock peening without coating induced residual stress distribution, wettability characteristics and enhanced pitting corrosion resistance of austenitic stainless steel." Applied Surface Science 428 (2018): 17-30.

[13] Montross, Charles S., Tao Wei, Lin Ye, Graham Clark, and Yiu-Wing Mai. "Laser shock processing and its effects on microstructure and properties of metal alloys: a review." International Journal of Fatigue 24, no. 10 (2002): 1021-1036.

[14] Kalainathan, S., and S. Prabhakaran. "Recent development and future perspectives of low energy laser shock peening." Optics \& Laser Technology 81 (2016): 137-144.

[15] Seok, Moo-Young, In-Chul Choi, Joonoh Moon, Sungju Kim, Upadrasta Ramamurty, and Jae-il Jang. "Estimation of the Hall-Petch strengthening coefficient of steels through nanoindentation." Scripta Materialia 87 (2014): 49-52.

[16] Sano, Yuji, Koichi Akita, Kiyotaka Masaki, Yasuo Ochi, Igor Altenberger, and Berthold Scholtes. "Laser peening without coating as a surface enhancement technology." Pulse 100, no. 40 (2006): 250mJ. 
[17] Gill, Amrinder S., Abhishek Telang, and Vijay K. Vasudevan. "Characteristics of surface layers formed on inconel 718 by laser shock peening with and without a protective coating." Journal of Materials Processing Technology 225 (2015): 463-472.

[18] Mannava, Seetharamaiah, Todd J. Rockstroh, and James G. Kelley. "Laser shock peening using low energy laser." U.S. Patent 5,932,120, issued August 3, 1999.

[19] Zhang, Xie, Tilmann Hickel, Jutta Rogal, Sebastian Fähler, Ralf Drautz, and Jörg Neugebauer. "Structural transformations among austenite, ferrite and cementite in $\mathrm{Fe}-\mathrm{C}$ alloys: A unified theory based on ab initio simulations." Acta Materialia 99 (2015): 281-289.

[20] Khot, Kishorkumar V., Sawanta S. Mali, Nita B. Pawar, Rohini R. Kharade, Rahul M. Mane, Vijay V. Kondalkar, Pallavi B. Patil et al. "Development of nanocoral-like Cd (SSe) thin films using an arrested precipitation technique and their application." New Journal of Chemistry 38, no. 12 (2014): 5964-5974.

[21] Fournier, J., P. Ballard, P. Merrien, J. Barralis, L. Castex, and R. Fabbro. "Mechanical effects induced by shock waves generated by high energy laser pulses." Journal de Physique III 1, no. 9 (1991): 1467-1480.

[22] L. Petan, J. Ocaña, J. Porro and Janez Grum. "Potential Improvements of Mechanical Properties of Maraging Steels After Laser Shock Peening (LSP)." Int. Journ. of Peening Science and Technology no.1 (2018): 61-73.

[23] Zhang, Xie, Tilmann Hickel, Jutta Rogal, Sebastian Fähler, Ralf Drautz, and Jörg Neugebauer. "Structural transformations among austenite, ferrite and cementite in $\mathrm{Fe}-\mathrm{C}$ alloys: A unified theory based on ab initio simulations." Acta Materialia 99 (2015): 281-289.

[24] Fitzgerald, Steven P. "Frank-Read sources and the yield of anisotropic cubic crystals." Philosophical Magazine Letters 90, no. 3 (2010): 209-218. 
[25] Frank, F. C., and W. T. Read Jr. "Multiplication processes for slow moving dislocations." Physical Review 79, no. 4 (1950): 722.

[26] Brown, Matthew S., and Craig B. Arnold. "Fundamentals of laser-material interaction and application to multiscale surface modification." Laser precision microfabrication 135 (2010): 91-120.

[27] Toji, Yuki, Hiroshi Matsuda, and Dierk Raabe. "Effect of Si on the acceleration of bainite transformation by pre-existing martensite." Acta Materialia 116 (2016): 250-262.

[28] Sajjadi, Seyed Abdolkarim, and Seyed Mojtaba Zebarjad. "Isothermal transformation of austenite to bainite in high carbon steels." Journal of materials processing technology 189, no. 1 (2007): 107-113.

[29] Meyers, M. A., G. Subhash, B. K. Kad, and L. Prasad. "Evolution of microstructure and shear-band formation in $\alpha$-hcp titanium." Mechanics of Materials 17, no. 2-3 (1994): 175-193.

[30] Hansen, Niels. "Hall-Petch relation and boundary strengthening." Scripta Materialia 51, no. 8 (2004): 801-806.

[31] Song, W., J. Von Appen, P. Choi, R. Dronskowski, D. Raabe, and W. Bleck. "Atomic-scale investigation of $\varepsilon$ and $\theta$ precipitates in bainite in $100 \mathrm{Cr} 6$ bearing steel by atom probe tomography and ab initio calculations." Acta Materialia 61, no. 20 (2013): 7582-7590.

[32] Morales-Rivas, Lucia, Alejandro González-Orive, Carlos Garcia-Mateo, Alberto Hernández-Creus, Francisca G. Caballero, and Luis Vázquez. "Nanomechanical characterization of nanostructured bainitic steel: Peak Force Microscopy and Nanoindentation with AFM." Scientific reports 5 (2015).

[33] Chen, Bo, Jun Jiang, and Fionn PE Dunne. "Is stored energy density the primary meso-scale mechanistic driver for fatigue crack nucleation?." International Journal of Plasticity (2017).

[34] Sano, Y., K. Masaki, T. Gushi, and T. Sano. "Improvement in fatigue performance of friction stir welded A6061-T6 aluminum alloy by laser peening without coating." Materials \& Design (1980-2015) 36 (2012): 809-814. 
[35] Moćko, W. "The influence of stress-controlled tensile fatigue loading on the stress-strain characteristics of AISI 1045 steel." Materials \& Design 58 (2014): 145-153.

\section{Highlights}

- Current research presents the low energy laser shock peening without coating enhanced surface properties of ultrafine bainitic steel

- The martensite phase transformations trend and the lattice misorientation in the crystalline structure was analysed

- The microstructural grain refinement features such as nano-twins, micro shear bands and shear cells are observed

- The high strain work hardened depth-wise modified mechanical properties are mitigated the fatigue failures significantly 